\title{
The Platino project: methodology of a multicenter prevalence survey of chronic obstructive pulmonary disease in major Latin American cities
}

\author{
Ana MB Menezes*1, Cesar G Victora1, Rogelio Perez-Padilla ${ }^{2}$ and the \\ PLATINO Team ${ }^{3}$
}

\begin{abstract}
Address: ${ }^{1}$ Federal University of Pelotas - Av. Duque de Caxias, 250 - Third Floor - CEP: 96030-000 - Pelotas, Rio Grande do Sul, Brazil, ${ }^{2}$ Institute of Respiratory Diseases, Mexico - Instituto Nacional de Enfermedades Respiratorias. Tlalpan, 4502, Mexico DF, Mexico 14080 and ${ }^{3}$ PLATINO Team: Av. Duque de Caxias, 250 - Third Floor - CEP: 96030-000 - Pelotas, Rio Grande do Sul, Brazil
\end{abstract}

Email: Ana MB Menezes* - anamene@terra.com.br; Cesar G Victora - cvictora@terra.com.br; Rogelio Perez-

Padilla - perezpad@servidor.unam.mx

* Corresponding author

BMC Medical Research Methodology 2004, 4:15 doi:10.1 186/147|-2288-4-15

Accepted: 17 June 2004

This article is available from: http://www.biomedcentral.com/I47I-2288/4/15

(C) 2004 Menezes et al; licensee BioMed Central Ltd. This is an Open Access article: verbatim copying and redistribution of this article are permitted in all media for any purpose, provided this notice is preserved along with the article's original URL.

\begin{abstract}
Background: The prevalence of Chronic Obstructive Pulmonary Disease (COPD) in many developed countries appears to be increasing. There is some evidence from Latin America that COPD is a growing cause of death, but information on prevalence is scant. It is possible that, due to the high frequency of smoking in these countries, this disease may represent a major public health problem that has not yet been recognized as such. The PLATINO study is aimed at measuring COPD prevalence in major cities in Latin America.

Methods/Design: A multi-country survey is being carried out in major cities in Latin America. In each metropolitan area, a population-based sample of approximately I,000 individuals aged 40 years or older is being interviewed using standardized questionnaires. Eligible subjects are submitted to pre- and postbronchodilator spirometry, and classified according to several criteria for COPD. Anthropometric examinations are also performed. Several risk factors are being studied, including smoking, socioeconomic factors, exposure to domestic biomass pollution, occupational exposure to dust and hospital admissions due to respiratory conditions during childhood. Whether or not subjects affected by COPD are aware of their disease, and if so how it is being managed by health services, is also being investigated, as are the consequences of this condition on quality of life and work performance.

Results: At the present time, the study is completed in São Paulo, Mexico City and Montevideo; Chile has started the study in March 2004 and it will be followed by Venezuela; two other metropolitan areas could still join the PLATINO project. Similar sampling procedures, with stratification for socio-economic status, are being used in all sites. Strict coordination, training and standardization procedures have been used to ensure comparability of results across sites. Overall $92 \%$ of the pre-bronchodilator spirometry tests fulfilled ATS criteria of quality in the three first sites (97\% in Montevideo, $91 \%$ in Mexico and $89 \%$ in Sao Paulo).

Conclusions: The PLATINO project will provide a detailed picture of the global distribution of COPD in Latin America. This project shows that studies from Latin America can be carried out with adequate quality and be of scientific value.
\end{abstract}




\section{Background}

Although Chronic Obstructive Pulmonary Disease (COPD) is one of the most relevant public health problems in Latin America, few data are available on its prevalence and risk factors. Only one population-based study is available, from a city in Southern Brazil [1]. The lack of studies is of even greater concern in face of the high prevalence of smoking in the region, ranging from $11.3 \%$ in females (Colombia) to $49.6 \%$ in males (Chile) [2-7]. For both sexes combined, the median prevalence of smoking from published studies is around 30\%.

The burden of respiratory diseases in Latin America is also high. According to the "Global Burden of Disease" project, the estimated number of COPD deaths in the Region increased from 57,000 in 1990 to 95,000 in 2000 [8]. COPD is predicted to be the fifth largest cause of disability by 2020 .

The present multi-country survey, the PLATINO project (Proyecto LatinoAmericano de Investigación en Obstrucción Pulmonar), is aimed at measuring the prevalence of COPD in some major cities of Latin America using standardized methodology. It will also provide information on the main risk factors for this important condition.

\section{Brief history and planning of the study}

In 2001, the Latin American Thorax Association (Asociación Latinoamericana del Tórax - ALAT - Department of COPD) decided to promote a multi-country survey to help fill in the information gaps about COPD prevalence and risk factors in the Region. It was initially decided that five major cities from different countries would be included: Sao Paulo (Brazil), Santiago (Chile), Mexico City (Mexico), Bogota (Colombia) and Buenos Aires (Argentina). An outline project was prepared by early 2002 and it was established that the Coordinating Centre (CC) would be in Pelotas, Southern Brazil. Although Uruguay and Venezuela were not one of the countries originally involved in PLATINO, local teams became strongly interested and both countries were included as sites of PLATINO.

At the same time, another group of researchers was developing a similar protocol - the Burden of Obstructive Lung Disease (BOLD) survey - to be carried out in China, United States and other sites. It was agreed that the PLATINO and BOLD teams would work together in the protocol to make sure that the basic methodological approaches and data collection instruments would be comparable for both studies.

\section{Study organization}

The organizational framework for the multi-center study includes three committees. Representatives from ALAT, the overall study coordinator and the principal investigators from each site make up the Steering Committee, which has full responsibility for the design and implementation of the study. The Executive Committee includes the overall coordinator, the coordinator for spirometry, and the director of the ALAT department of COPD. The Advisory Committee includes prominent external experts on the subject who, when requested by the Steering Committee, provide guidance on study design, implementation and analysis.

The study secretariat and the units of epidemiology, biostatistics and computing are located in Pelotas (Brazil). Mexico was chosen as the site to be responsible for training and quality control of spirometric examinations. Each study center has its own principal investigator.

\section{Methods/Design}

A cross sectional design aimed at obtaining representative samples of adults aged 40 years or more is used. Subjects aged less than 40 years are not included because COPD prevalence is low in this age range [9]. Exclusion criteria include mental disease precluding response to the questionnaire and long-term institutionalization. Individuals temporarily admitted to a hospital when the sample was selected are interviewed on a later occasion, after dismissal from hospital.

To date, the following major metropolitan areas in Latin America are included in the study so far: Sao Paulo (Brazil), Mexico City (Mexico), Montevideo (Uruguay), Santiago (Chile) and Caracas (Venezuela). Contacts are being made to decide the inclusion of next sites, such as (Buenos Aires (Argentina) and Bogotá (Colombia). These sites were chosen because of their geographical position, population size and the availability of collaborating research centers. They represent the different geographical areas of Latin America (Figure 1) and the largest metropolitan area in each of the selected countries.

\section{Sample size}

Calculations were based on prevalence scenarios from published studies, with COPD prevalence ranging from 5 to $60 \%$, a margin of error not more than four percentage points, 95\% confidence intervals, and a design effect of 1.5 based on a previous survey in the region [1]. Allowing a $20 \%$ margin of safety for non-response, samples of approximately 1,000 subjects in each site are required. Sample size requirements were also calculated for detecting an association between COPD and smoking (main risk factor) using the following parameters: confidence level of $95 \%$, power of $80 \%$, smoking prevalence of $30 \%$, relative risk of 2.0 , with an additional $10 \%$ for nonresponse and $15 \%$ for confounder adjustment. This calculation requires samples of 940 individuals in each site. By 


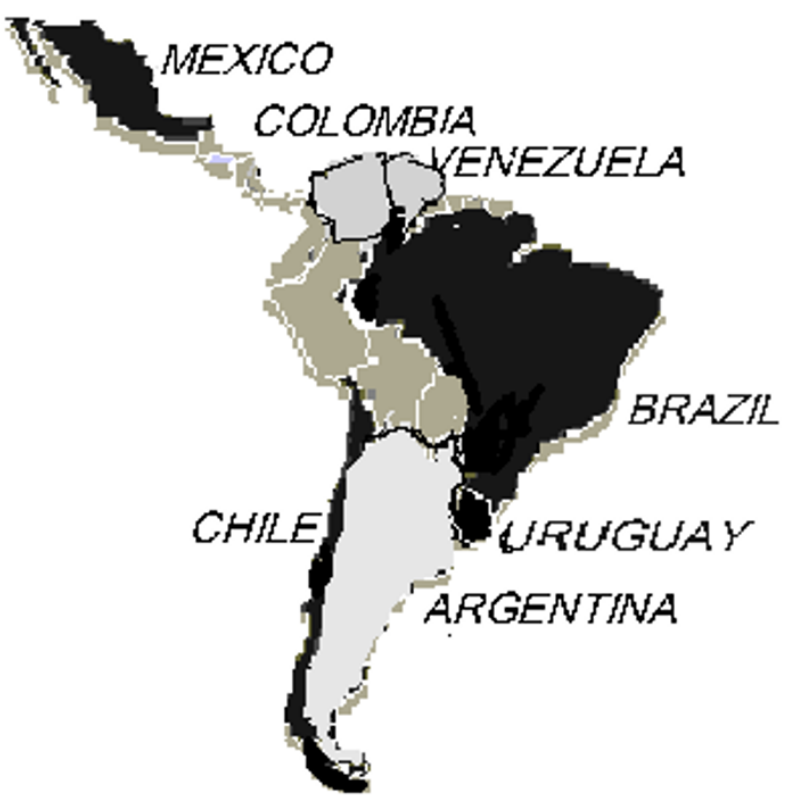

Figure I

Latin American countries included in the PLATINO project (black); and potential sites (light gray)

pooling data from the different sites, it will also be possible to detect smaller relative risks and to study the effect of the risk factors discussed below.

\section{Sampling procedure}

To obtain representative samples of adults living in the metropolitan areas of each site, a multi-stage cluster sampling strategy is used. All sites use the same basic procedures for sampling, with minor local adaptations as required. Metropolitan areas are stratified into the main city and other municipalities; further stratification (implicit or explicit) is used for socioeconomic status variables, which vary from country to country based on data availability. Sixty-eight census tracts are selected in each site, taking the stratification into account and using probability proportionate to the number of households in each tract, based on the last census. Within each tract, all households are listed and the total count is updated; the ratio between the expected number of households and the actual count is used to calculate the number of households to be sampled from that tract. On average, 15 households are expected to be selected from each tract, but this number is larger for tracts where the number of households has increased since the last census, and smaller for tracts where it has declined. Then, systematic sampling is used to select households from the updated listings. All adults aged 40 years or more living in the selected households are included in the study.

\section{Primary outcome}

The main outcome of the study is the prevalence of COPD measured by spirometry, as defined by a post-bronchodilator $\mathrm{FEV}_{1} / \mathrm{FVC}<0.70$. To allow comparison with other studies, additional outcomes are also measured (Table 1).

\section{Risk factors and COPD impact}

The following risk factors are collected in all sites: sex; age in years; skin color/ethnicity (self reported); educational level (complete years of formal schooling) of the interviewee and his/her father; occupational exposure to dust (reported duration and frequency of exposure); smoking history (daily amount, age at beginning and stopping, type of cigarette, current status); passive smoking (exposure at home in the previous two weeks); domestic exposure to coal and biomass smoke (from cooking or heating); hospital admissions due to a respiratory illness during childhood; and family history of lung disease (history of chronic bronchitis, emphysema, or COPD among parents or siblings). Anthropometric status (weight, height, and abdominal circumference) is evaluated using standardized methods and the instruments described below. Body mass index (weight in kilograms / square of height in meters) is calculated.

An additional questionnaire module addresses whether or not subjects affected by COPD are aware of their disease, and if so how it is being managed by health services, including diagnostic tests, pharmacological management, and prevention of infections. The consequences of COPD are also investigated; including work absenteeism, hospital admissions, and disease impact on quality of life.

\section{Instruments and examinations}

The questionnaire is a composite including sections of the following questionnaires: ATS/DLD [14], ECRHS II [15], Lung Health Study (LHS) [16] and SF-12 [17] (to assess overall health status). For the Brazil site, questionnaires were written in English and then translated to Portuguese. Study instruments were pre-tested in the Coordinating Centre. After the last version of all instruments in English and Portuguese, a back translation into English was done to ensure that the content of the questions remained unchanged. A similar procedure was used for the Spanish version applied in the other study sites. A copy of the questionnaire is available upon request. When a subject refuses to participate, he/she is asked to answer a short questionnaire including information on age, sex, smoking and reported presence of COPD, asthma or chronic bronchitis. 
Table I: Outcome criteria in the PLATINO project.

\begin{tabular}{|c|c|}
\hline Outcome & Definition* \\
\hline \multicolumn{2}{|c|}{ Spirometric criteria* } \\
\hline FIXED RATIO & Post-bronchodilator $\mathrm{FEV}_{\mathrm{I}} / \mathrm{FVC}<70 \%[10]$ \\
\hline GOLD & Post-bronchodilator $\mathrm{FEV}_{1} / \mathrm{FVC}<70$ and $\mathrm{FEV},<80 \%$ of predicted value $[10]$ \\
\hline ATS & Post-bronchodilator $\mathrm{FEV} / \mathrm{FVC}$ below the $5^{\text {th }}$ percentile and $\mathrm{FEV},<100 \%$ of predicted value $[\mathrm{II}]$ \\
\hline ERS & Post-bronchodilator $\mathrm{FEV}_{1} / \mathrm{FVC}<88 \%$ of the predicted value for men and $<89 \%$ for women [12] \\
\hline \multicolumn{2}{|r|}{ 年 } \\
\hline Chronic bronchitis & Cough with phlegm for at least 3 months a year in the last 2 years \\
\hline Asthma & Wheezing within the last 12 months \\
\hline Emphysema & Breathlessness due to exercise \\
\hline \multicolumn{2}{|l|}{ Medical diagnosis } \\
\hline COPD & Reported lifetime diagnosis of COPD \\
\hline Chronic bronchitis & Reported lifetime diagnosis of chronic bronchitis \\
\hline Emphysema & Reported lifetime diagnosis of emphysema \\
\hline Asthma & Reported lifetime diagnosis of asthma \\
\hline
\end{tabular}

FEVI = forced expiratory volume in the first second; FVC = forced vital capacity For initial analyses of lung function measurements, the NHANES III Mexican American reference values were used [13].

Height is measured with a portable Seca ${ }^{\circledast}$ stadiometer (precision $0.1 \mathrm{~cm}$ ) using the technique recommended by Lohman [18]. For weight, an electronic Tanita ${ }^{\circledast}$ scale (precision $200 \mathrm{~g}$ ) is used. For waist circumference, an inextensible Fiberglass ${ }^{\circledast}$ tape (precision $0.1 \mathrm{~cm}$ ) is used; the measurement is taken at the midpoint between the last rib and the iliac crest. Subjects are examined in light clothing and without shoes. All anthropometric measurements are carried out twice on each subject, and the average value is used.

\section{Spirometric examination}

Subjects who, in the last three months, have had thoracic or abdominal surgery, heart attack, eye surgery (or retinal detachment) or hospitalization due to a cardiovascular problem are excluded. The same applies for those undergoing tuberculosis treatment, pregnant women, or subjects with a pulse rate above 120 beats/minute.

Information is also obtained on the following variables: respiratory infection in the last three weeks; pulmonary medication in the last three hours; smoking in the last two hours; and vigorous exercise in the last hour. However, these are not considered as exclusion criteria.

Measurements are taken with identical portable, battery operated, ultrasound transit-time based EasyOne ${ }^{\mathrm{TM}}$ spirometers (Medical Technologies, Chelmsford, Massachusetts and Zürich, Switzerland). Calibration is checked daily with a three-liter syringe. Test results stored in the spirometer memory are downloaded daily to a computer.

The initial evaluation comprises a short questionnaire to determine whether the subject is eligible for spirometry.
Subjects then perform a maximum of 8 forced expiratory maneuvers to obtain three ATS acceptable measurements, with FVC and $\mathrm{FEV}_{1}$ reproducible to $150 \mathrm{ml}$. A beta agonist bronchodilator (albuterol $200 \mathrm{mcg}$ ) is then administered by inhalation through a $500 \mathrm{ml}$ spacer, and the test is repeated 15 minutes later, with the same criteria. All spirometric examinations are carried out with the subject seated, wearing a nose clip and a disposable mouthpiece. All field methods are tested in pilot studies in each site.

\section{Personnel, training and logistics}

In each country, the local team is trained by the main study coordinator, two experts in spirometry from Mexico, the local principal investigator (PI), two to three fieldwork supervisors, and a local anthropometrist. Interviewers must have at least full secondary education. Training lasts one week in each site, and additional time is spent with interviewers whose performance in the standardization sessions is sub optimal, until it becomes satisfactory. At the end of the training period, which includes several practical sessions, the following criteria are used to certify that interviewers perform adequately:

- Anthropometry: acceptable levels of intra and interobserver variability are $1.0 \mathrm{~cm}$ for waist circumference and $0.2 \mathrm{~cm}$ for height [19].

- Spirometry: all interviewers are given the same training for two full days, with a program fulfilling NIOSH training course in spirometry. During the two days the technicians test at least 10 subjects under supervision. Finally the technicians had to be approved in a practical examination and awarded a certificate. Previous experience of selected technicians in spirometry was variable 
depending on the site. Montevideo technicians had a university degree in cardiorespiratory technology, a career including training in pulmonary function testing. In Sao Paulo, the group of technicians were respiratory physiotherapists with no previous experience in spirometry, whereas in Mexico, educational backgrounds were diverse but most had been certified as spirometrists before the survey. Neither Sao Paulo nor Mexico had formal programs to train pulmonary function technicians.

- Questionnaires: interviewers carry out an interview in the presence of a supervisor and are approved if their performance is satisfactory.

The fieldwork in each site is planned to last an average of four months. Each study team includes on average three scouts, 14 interviewers, three field supervisors, a local spirometry supervisor and a secretary. The fieldwork includes several steps:

- The first visit to the sampled households is carried out by the scouts, who determine if there are eligible subjects present and deliver an official letter explaining the aim of the study. The study supervisors then contact subjects in order to arrange the best time for the interview.

- On the scheduled day, a pair of interviewers visit the household to apply the questionnaire and carry out all measurements; if the subject is not available on that day, several attempts are made until the interview and examination was completed.

- Interviewers visit the study headquarters at the beginning of each workday to check the calibration of the equipment and to receive a list of the households to be covered. On this occasion, spirometry results obtained in the previous day are downloaded.

\section{Results (Quality control)}

Rigorous procedures are used to ensure to standardize data quality across sites. These include:

\section{Spirometry}

An experienced technician on pulmonary function testing served as a field supervisor in each site and was in charge of checking instrument calibration every day. Calibration data is kept in the spirometer memory and database. After each test, the automated spirometer provides an evaluation of the quality of readings, based on the repeatability of the three "best" maneuvers. The aim is to obtain a grade "A" test according to this on-the-spot evaluation requiring three acceptable maneuvers, with the two highest FVC and $\mathrm{FEV}_{1}$ values within $150 \mathrm{ml}$. This is stricter than the $200 \mathrm{ml}$ required by the American Thoracic Society criteria [20]. The spirometry supervisor reviewed daily the flow-volume

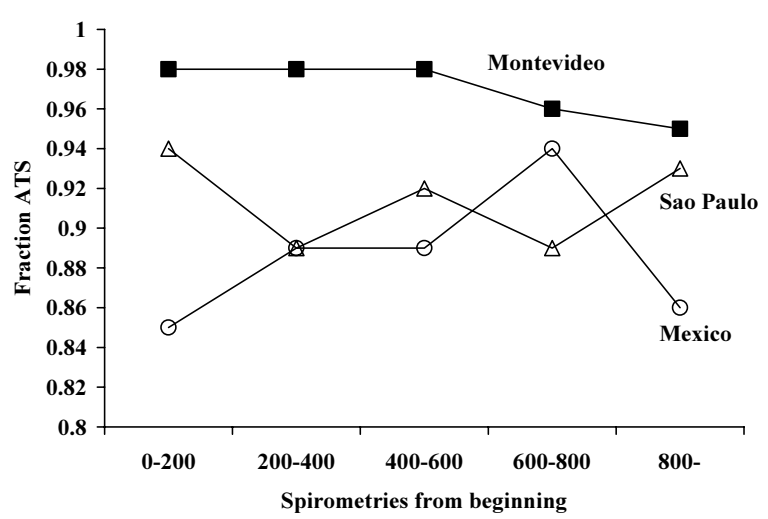

\section{Figure 2}

Fraction of spirometry tests fulfilling American Thoracic Society criteria in three centers of PLATINO (Sao Paulo, Mexico, Montevideo)

and volume-time curves to check quality and provided immediate feedback to technicians. During data collection, all spirometry results are sent weekly to Mexico using electronic data transfer. The Mexican team analyzes spirometry quality and provides weekly reports with assessments of each technician. Technicians are informed individually of their performance and their main quality problems, in order to improve. At the same time the local spirometry supervisor also checks these results daily including the volume-time and flow-volume curves, and works with the interviewers to correct any inaccuracies. Overall $92 \%$ of the pre-bronchodilator spirometry tests fulfilled ATS criteria of quality in the three first sites $(97 \%$ in Montevideo, $91 \%$ in Mexico and $89 \%$ in Sao Paulo). In addition $85 \%$ of the tests reached quality grade $\mathrm{A}$, that is a reproducibility of $\mathrm{FEV}_{1}$ and $\mathrm{FVC}$ to $150 \mathrm{~mL}(95 \%$ in Montevideo, $85 \%$ in Mexico and $77 \%$ in Sao Paulo). At the end of the testing period an opportunity was given to repeat poor quality tests. Figure 2 shows the fraction of spirometries according to the ATS quality criteria. At least $90 \%$ of the tests were carried out on naïve subjects.

\section{Interviews}

the supervisors repeat $10 \%$ of the interviews within two weeks after the initial contact. A short questionnaire is used, including six questions from the main questionnaire. Kappa statistics are calculated to measure reliability.

\section{Anthropometry}

Half way through the fieldwork period, all interviewers undergo refresher training in anthropometry, followed by a second round of standardization sessions. 


\section{Data processing and analyses}

All questionnaires are photocopied in each site, and the originals sent to the $\mathrm{CC}$, while a copy remains in the local site. In the $\mathrm{CC}$, all questionnaires are reviewed, open answers are coded and data is entered twice in an Epi-Info database [21]. The spirometry results were entered in Mexico in a STATA [22] database. After spirometry results are cleaned and edited, the database is sent to the CC and linked to the questionnaire database. A full copy of the final dataset is then sent to each site.

Analyses are carried out using the STATA program. These include descriptive analyses of the prevalence of outcomes and risk factors, as well as crude and multivariable analyses. For the multivariable analyses, Poisson regression models are used to provide estimates of adjusted prevalence ratios and their 95\% confidence intervals [23]. All analyses take into account the cluster sampling procedure. Confounding variables are retained in regression models if they reach a significance level of $\mathrm{p}=0.20 \mathrm{using}$ the Wald test; a significance level of $\mathrm{p}<0.05$ is used for identifying significant risk factors. Tests for linear trend are employed as appropriate.

The first site to start the study was Sao Paulo, where data collection took place from January to May 2003. The next site was Mexico City, where fieldwork was carried out from July to December 2003. Uruguay was the third site to start the study, and data were collected from October 2003 to January 2004. Fieldwork in Santiago is expected to start in early 2004. Additional centers will be defined during 2004, and it is hoped that by the end of 2004 five centers will have complete data.

\section{Ethical considerations}

Ethical approval is obtained from the ethical committee of each participating institution. Written informed consent is obtained from each subject. A T-shirt with the study logo, as well as the disposable mouthpieces and spacers, are presented to each subject as a souvenir of the study. The spirometric results are mailed to each subject ten days after the interview with an explanation of the results in lay language. Those diagnosed with COPD or another abnormality are invited to attend a medical consultation in the participating institution. Keeping identification records separate from the files with study results ensures confidentiality.

\section{Discussion}

\section{Lessons learned}

The PLATINO project will provide prevalence data on COPD from population-based samples of large metropolitan areas in Latin America. It will also measure associations between COPD and selected risk factors. Although the sample is not representative of Latin America as a whole - which would require an extremely ambitious and costly study - this is the first multi-center survey on this topic encompassing multiple developing countries.

We believe that several aspects of the planning and design of the PLATINO study have contributed to its success. First, the close involvement of ALAT in all aspects of the study has led to the involvement of experienced researchers from several countries. In particular, coordination with BOLD makes it possible to compare findings from the PLATINO studies with surveys performed in other countries, since both projects have adopted the same instruments and methodological principles. The close coordination between these studies is an example of mutually beneficial interaction that should be pursued by other teams of researchers.

Second, the organization of the study is contributing to its success under sometimes difficult conditions. By establishing a Coordinating Centre with a large experience in epidemiological research, coordinated training and standardization of all study sites by the same team may be carried out immediately prior to the beginning of field work in each site. This tight coordination allows the sequential initiation of data collection on a site-by-site basis (instead of starting several sites simultaneously) and allows the coordination team to be present at the launch of each study. This permits lessons learned in one site to be applied to the next surveys through early detection and correction of identified problems. Similarly, the selection of a single Centre exclusively for the evaluation and quality control of spirometric examinations places the same researcher in charge of quality control for all sites. By using electronic transmission of examination results on a weekly basis, tight quality control of spirometry is maintained on a "real time" basis, and problems in this area may be addressed as they occur. Quality of spirometries was good, and subjects could provide spirometry tests fulfilling ATS criteria and most of them better reproducibility than recommended by ATS. Site variations in quality can be attributed mostly to technicians' background, but which no doubt includes growing experience of field supervisors, training and central quality control.

Third, key methodological decisions contribute to the utility of PLATINO results. The adoption of a common sampling strategy for all sites ensures the comparability of results across sites and allows pooled analyses. The reliance on spirometry (pre- and post-bronchodilator) as the key diagnostic method for COPD and the use of multiple diagnostic indices ensures that results can be compared with those from previously published surveys [24]. The concurrent collection of anthropometric data - which is important for diagnosing COPD - also provides population-based information on overweight and obesity, 
conditions that are rapidly becoming epidemic in some developing countries [25].

Finally, the fact that only two similar languages (Spanish and Portuguese) are spoken in Latin America is essential for communication among all participants of the project.

The epidemiological transition is leading to sharp increases in chronic diseases in developing countries. COPD and overweight/obesity, for example, are predicted to become leading causes of morbidity and mortality in the near future [25]. Research findings from developed countries cannot be automatically extrapolated to populations which, for example, may be exposed to domestic biomass pollution, home-made cigarettes or fetal or childhood malnutrition. Thus, experience in population-based surveys of chronic diseases and their risk factors will become increasingly important in coming years. The PLATINO project shows that researchers from less developed countries can carry out complex studies involving several countries, and providing robust results with wide policy implications.

\section{Acknowledgements}

Grant: This project is supported by Boehringer Ingelheim $\mathrm{GmbH}$.

We would like to acknowledge Claus Justus (representing the study sponsor of the Platino Project) for all the logistical support and valuable advice offered during the conduct of the study; to Ron Halbert for his excellent comments for improving the writing of this paper; to the Members of the Platino team:

- Principal investigators: Jardim JRB; Perez-Padilla R; Muiño A; Lopez M; Valdivia G; Torres C.

- Advisory Committee: Celli B; Buist S; Miravitlles M; Vollmer W; Roisin RR.

- Executive Committee: Luna J; Lisboa C.

\section{References}

I. Menezes AM, Victora CG, Rigatto M: Prevalence and risk factors for chronic bronchitis in Pelotas, RS, Brazil: a populationbased study. Thorax 1994, 49:1217-1221.

2. Ministério da Saúde (MS), (INAN) Instituto Nacional de Alimentação e Nutrição: Pesquisa Nacional sobre saúde e nutrição (PNSN): estatísticas sobre hábitos de fumo no Brasil. Brasília, INAN; 1989

3. Socio-economic status and risk factors for cardiovascular disease: a multicentre collaborative study in the International Clinical Epidemiology Network (INCLEN). The INCLEN Multicentre Collaborative Group. I Clin Epidemio 1994, 47: | 401 - I 409.

4. Consejo Nacional para el Control de Estupefacientes (CONACE): Estudios nacionales sobre consumo de drogas en la población general de Chile. 1998 [http://www.conace.gov.cl].

5. Sesma-Vazquez S, Campuzano-Rincon JC, Carreon-Rodriguez VG, Knaul F, Lopez-Antunano FJ, Hernandez-Avila M: Trends of tobacco demand in Mexico: 1992-1998. Salud Publica Mex 2002, 44 Suppl I:S82-92.

6. Poletto L, Pezzotto SM, Morini J, Andrade J: Prevalence of smoking in young people and their parents. Important associa- tions with education and occupation. Rev Saude Publica |99|, 25:388-393

7. World Health Organization (WHO), Centers for Diseases Control and Prevention (CDC): Global Youth tobacco survey (GYTS). 1999 [Available in: http://www.cdc.gov/tobacco/global/GYTS.htm]

8. Murray CIL, Lopez AD: The Global Burden of Disease. Geneva, WHO Harvard University Press; 1996.

9. Burrows B: An overview of obstructive lung diseases. Med Clin North Am 198I, 65:455-47I.

10. Global Initiative for Chronic Obstructive Lung Disease. Global strategy for the diagnosis, management, and prevention of choronic obstrustive pulmonary disease. 200 I [http://gold copd.com]. National Heart, Lung and Blood Institute

II. Standards for the diagnosis and care of patients with chronic obstructive pulmonary disease. American Thoracic Society. Am J Respir Crit Care Med 1995, I 52:S77-I 21.

12. Quanjer PH, Tammeling G], Cotes JE, Pedersen OF, Peslin R, Yernault JC: Lung volumes and forced ventilatory flows. Report Working Party Standardization of Lung Function Tests, European Community for Steel and Coal. Official Statement of the European Respiratory Society. Eur Respir J Suppl 1993, 16:5-40.

13. Hankinson JL, Odencrantz JR, Fedan KB: Spirometric reference values from a sample of the general U.S. population. Am J Respir Crit Care Med 1999, I 59:179-187.

14. Ferris BG: Epidemiology Standardization Project (American Thoracic Society). Am Rev Respir Dis 1978, I I 8: I- I 20.

15. ECRHS: European Community Respiratory Survey II. 2004 [http://ecrhs.org/quest.com].

16. Lung Health Study Questionaire 2004 [http://bccrc.ca/down load/ci/lc02 questionaire.doc].

17. Ware JE, Kosinski M, Keller SD: How to score the SFI 2 Physical and Mental Health Summary Scales. 2nd edition. Boston, The Health Institute; 1995.

18. Lohman TG, Roche AF, Martorell R: Anthropometric Standardization Reference Manual. Champaing, Human Kinetics Books; 1988.

19. Habicht JP: Standardization of quantitative epidemiological methods in the field. Bol Oficina Sanit Panam 1974, 76:375-384.

20. Standardization of Spirometry, 1994 Update. American Thoracic Society. Am J Respir Crit Care Med 1995, I 52: I I07-I I 36.

21. Centers for Disease Control and Prevention (CDC): Epi Info, Version 6.04d. Atlanta, Georgia, CDC; 2004.

22. StataCorp: Stata statistical software. 7.0 th edition. College station Tx: stata corporation; 200I.

23. Barros AJ, Hirakata VN: Alternatives for logistic regression in cross-sectional studies: an empirical comparison of models that directly estimate the prevalence ratio. BMC Med Res Methodol 2003, 3:21.

24. Celli BR, Halbert RJ, Isonaka S, Schau B: Population impact of different definitions of airway obstruction. Eur Respir J 2003, 22:268-273.

25. Uauy R, Albala C, Kain J: Obesity trends in Latin America: transiting from under- to overweight. I Nutr 200 I, I 3 I:893S-899S.

\section{Pre-publication history}

The pre-publication history for this paper can be accessed here:

http://www.biomedcentral.com/1471-2288/4/15/prepub 